\title{
Correction to: Services and simulation frameworks for vehicular cloud computing: a contemporary survey
}

Bilal Ahmed, Asad Waqar Malik*, Taimur Hafeez and Nadeem Ahmed

\section{Correction to: EURASIP J. Wirel. Commun. Netw.}

https://doi.org/10.1186/s13638-018-1315-y

Following publication of the original article [1], the authors flagged that this reference is missing from the article:

https://www.scalable-networks.com/qualnet-networksimulation

This reference should be in the References list at the end of the article, and it should be referenced at the two locations in the main body of the article where "QualNet" is referred to (namely, on pages 13 and 15 of the article PDF).

The authors apologize for this error.

Published online: 22 May 2019

\section{Reference}

1. Ahmed et al., Services and simulation frameworks for vehicular cloud computing: a contemporary survey. EURASIP J. Wirel. Commun. Netw. 2019, 4 (2019). https://doi.org/10.1186/s13638-018-1315-y

\footnotetext{
* Correspondence: asad.malik@seecs.edu.pk

The original article can be found online at https://doi.org/10.1186/s13638018-1315-y

Department of Computing, School of Electrical Engineering and Computer Science (SEECS), National University of Sciences and Technology (NUST), Islamabad, Pakistan
} 